\title{
Analysis of Behavior of Small Agglomerated Particles on Two- dimensional Vibrating Plate
}

\section{$\operatorname{AUTHOR}(\mathrm{S}):$}

Kobayakawa, Murino; Yasuda, Masatoshi; Matsusaka, Shuji

\section{CITATION:}

Kobayakawa, Murino ...[et al]. Analysis of Behavior of Small Agglomerated Particles on Two-dimensional Vibrating Plate. AlP Conference Proceedings: Powders and Grains 2013 2013, 1542: 991-994

ISSUE DATE:

2013-08-14

URL:

http://hdl.handle.net/2433/187983

\section{RIGHT:}

(c) 2012 American Institute of Physics. This article may be downloaded for personal use only. Any other use requires prior permission of the author and the American Institute of Physics. 


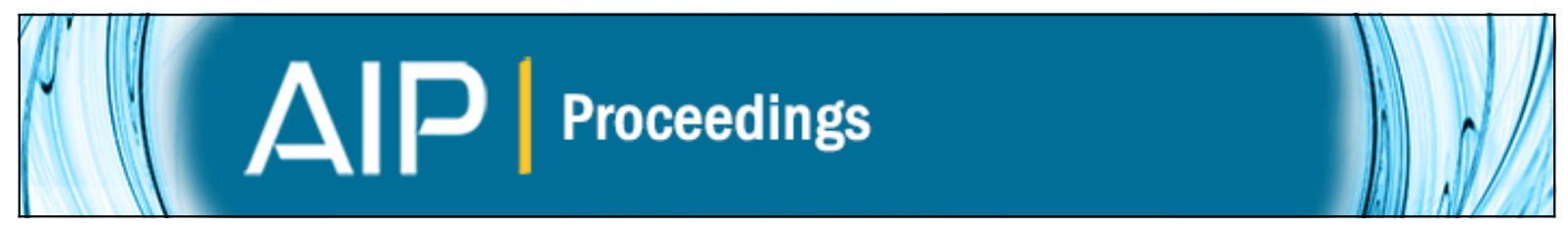

\section{Analysis of behavior of small agglomerated particles on two-dimensional vibrating plate}

Murino Kobayakawa, Masatoshi Yasuda, and Shuji Matsusaka

Citation: AIP Conference Proceedings 1542, 991 (2013); doi: 10.1063/1.4812100

View online: http://dx.doi.org/10.1063/1.4812100

View Table of Contents: http://scitation.aip.org/content/aip/proceeding/aipcp/1542?ver=pdfcov

Published by the AIP Publishing

\section{Articles you may be interested in}

Twodimensional experimental analysis of tire vibration

J. Acoust. Soc. Am. 107, 2901 (2000); 10.1121/1.428796

Vibrational properties of small twodimensional classical crystals

J. Chem. Phys. 103, 1718 (1995); 10.1063/1.469743

Resonant vibrations of fluidloaded plates. Twodimensional case.

J. Acoust. Soc. Am. 91, 2419 (1992); 10.1121/1.403187

Measuring vibration on plates and shells with twodimensional arrays

J. Acoust. Soc. Am. 76, S45 (1984); 10.1121/1.2021865

A Theory of TwoDimensional Longitudinal and Flexural Vibrations in Rectangular Isotropic Plates J. Appl. Phys. 6, 234 (1935); 10.1063/1.1745325 


\title{
Analysis of Behavior of Small Agglomerated Particles on Two-dimensional Vibrating Plate
}

\author{
Murino Kobayakawa $^{\text {a }}$, Masatoshi Yasuda ${ }^{\text {a, b }}$, Shuji Matsusaka ${ }^{\text {a }}$ \\ ${ }^{a}$ Department of Chemical Engineering, Kyoto University, Kyoto 615-8510, Japan \\ ${ }^{b}$ IMP, 67-20 Ichibu-cho, Ikoma-shi, nara 630-0222, Japan
}

\begin{abstract}
The movement of particles in the range from 0.5 to $500 \mu \mathrm{m}$ in mass median diameter on a two-dimensional vibrating plate is observed through a high-speed digital camera with a zoom lens. The results show that larger particles saltate higher, while smaller particles easily agglomerate and slightly saltate because of the low restitution of their loosely packed structure. The salation heights are in good agreement with the results calculated by a model based on gravity, adhesion, drag force, and restitution.
\end{abstract}

Keywords: vibration, fine particles, agglomerate, particle movement, restitution.

PACS: 07.10.-h

\section{INTRODUCTION}

For smaller particles, interaction forces between particle-particle and particle-substrate are stronger than gravity; thus fine particles easily agglomerate and cannot flow under gravity. To overcome the interaction forces, vibration is often used for powder handling processes in industry. There are many studies on the behavior of particles on a vibrating substrate; however, most studies have been carried out using noncohesive particles with diameters larger than several hundred micrometers ${ }^{1-5}$. There are few reports on the behavior of fine particles.

In this paper, four different particles in the range from 0.5 to $500 \mu \mathrm{m}$ in mass median diameter are examined. The behavior of the particles on a twodimensional vibrating plate is observed through a high-speed digital camera with a zoom lens. Furthermore, the vertical motion of the particles is studied by a model based on gravity, adhesion, drag force and restitution.

\section{THEORY}

The $x$ and $y$ coordinates are defined, where the $x$ axis and $y$ axis are tangential and vertical, upward, to the substrate, respectively. The displacement $y_{\mathrm{s}}$, velocity $v_{y \mathrm{~s}}$ and acceleration $\alpha_{y \mathrm{~s}}$ of the substrate are given by the following equations ${ }^{2,5}$ :

$$
\begin{aligned}
& y_{s}=A_{y} \sin \omega t \\
& v_{y s}=\frac{d y_{s}}{d t}=A_{y} \omega \cos \omega t
\end{aligned}
$$

$$
\alpha_{y s}=\frac{d^{2} y_{s}}{d t^{2}}=-A_{y} \omega^{2} \sin \omega t
$$

where $A_{\mathrm{y}}$ is the vertical vibration amplitude, $\omega$ is the angular velocity, and $t$ is the time. When the force caused by the vertical vibration acceleration, upward, is larger than the sum of gravity and adhesive force, particles can flight from the substrate.

$$
m_{p} A_{y} \omega^{2} \sin \omega t_{0}>F_{g}+F_{a}
$$

where $m_{p}$ is the mass of particle, $t_{0}$ is the time at start of flight, $F_{g}$ is the gravity, $F_{a}$ is the adhesive force. The motion equation of particles during flight is represented by

$$
m_{p} \frac{d^{2} y_{p}}{d t^{2}}=-F_{g}-F_{d}
$$

where $v_{p}$ is the vertical velocity of particle. $F_{d}$ is the drag force. For larger particles, $F_{d}$ can be neglected compared to $F_{g}$. The coefficient of restitution of particle-wall collisions $e$ is defined by the relative velocities before and after collision, i.e.

$$
e=-\frac{v_{p 2}-v_{s 2}}{v_{p 1}-v_{s 1}}
$$

The vertical motions of particles and the substrate can be calculated using Eqs (1)-(6).

\section{EXPERIMENTAL}

Figure 1 shows a schematic diagram of the experimental setup. A metal plate $\left(15 \times 15 \mathrm{~mm}^{2}\right)$, made of stainless steel (SUS304), was vibrated horizontally 
TABLE 1. Test particles.

\begin{tabular}{ccccc}
\hline No. & Material & $D_{p 50}(\mu \mathrm{m})$ & $\rho_{p}\left(\mathrm{~kg} / \mathrm{m}^{3}\right)$ & Manufacturer \\
\hline 1 & Alumina (spherical) & 500 & 4000 & Taimei Chemicals Co., Ltd. \\
2 & Alumina (spherical) & 50 & 4000 & Showa Denko K.K. \\
3 & Alumina (spherical) & 5 & 4000 & Showa Denko K.K. \\
4 & Alumina (irregular) & 0.5 & 4000 & Fujimi Incorporated \\
\hline
\end{tabular}

and vertically by two piezoelectric vibrators. The frequency, amplitude and phase of vibrations were controlled with a vibration control system (VST-01, IMP. Co., Ltd.).

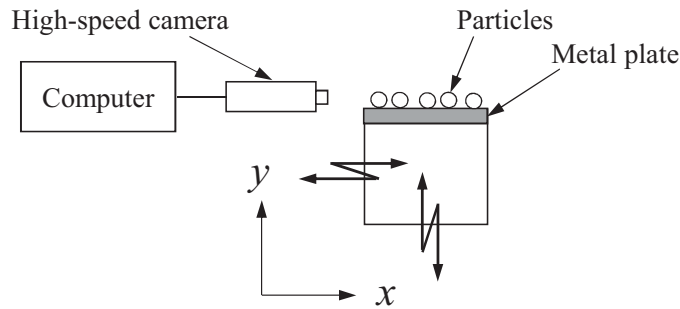

FIGURE 1. Schematic diagram of experimental setup.

Table 1 shows the properties of four different particles used. These particles were dried at $120{ }^{\circ} \mathrm{C}$ over $24 \mathrm{~h}$ and cooled down to room temperature in a desiccator. The behaviors of the particles on the vibrating plate were observed by a high-speed digital camera with a zoom lens (Fastcam-Max, Photron, Inc.). The height of particles during flight was obtained from images captured by the camera. The restitution coefficients of particle-wall collisions needed for the numerical calculation were determined from the results of the preliminary impact tests.

\section{RESULTS AND DISCUSSION}

Figure 2 shows the horizontal and vertical displacements of the plate obtained from the images. The signals applied to the piezoelectric vibrators were sine waves, where the frequency is $280 \mathrm{~Hz}$ and phase difference between two waves is zero. The experimental results showed that the plate can be stably vibrated and the vibrations in two directions are synchronized. Although this figure shows the $20 \mu \mathrm{m}$ in amplitude of vibration, the amplitude can be easily changed.

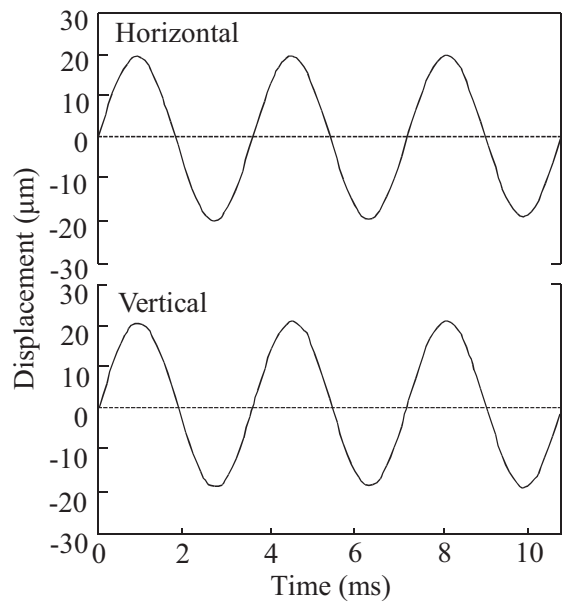

FIGURE 2. Displacement of vibrating substrate $\left(f=280 \mathrm{~Hz}, A_{x}=A_{y}=20 \mu \mathrm{m}\right)$.

Table 2 shows the ranges of the particle heights of the four different particles. The plate was vibrated at $f$ $=280 \mathrm{~Hz}, A_{y}=35 \mu \mathrm{m}$. For $D_{p 50}=500 \mu \mathrm{m}$ and $50 \mu \mathrm{m}$, all the particles saltate on the vibrating plate. For $D_{p 50}$ $=5 \mu \mathrm{m}$, particles adhered to the plate owing to the adhesive forces. As for $D_{p 50}=0.5 \mu \mathrm{m}$, particles formed small agglomerated particles $\left(D_{\text {ag50 }}=230 \mu \mathrm{m}\right)$, which slightly saltate on the vibrating plate. These results show that smaller particles generally have lower saltation heights.

TABLE 2. Height of particles during flight (vibrating plate: $f=280 \mathrm{~Hz}, A_{y}=35 \mu \mathrm{m}$ ).

\begin{tabular}{cc}
\hline$D_{p 50}(\mu \mathrm{m})$ & Height $(\mathrm{mm})$ \\
\hline 500 & $0-4.0$ \\
50 & $0-1.5$ \\
5 & 0 \\
0.5 & $0-0.2$ \\
\hline
\end{tabular}


a.

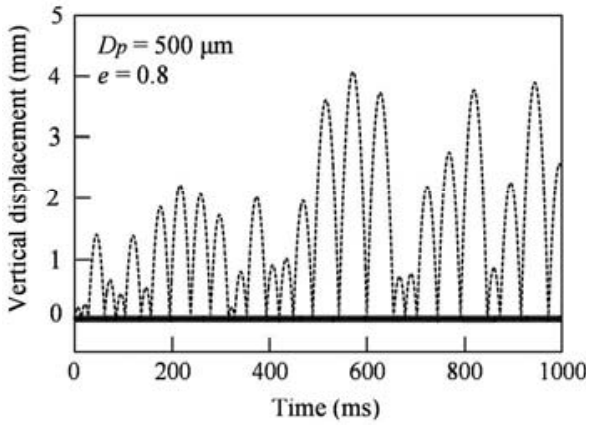

b.

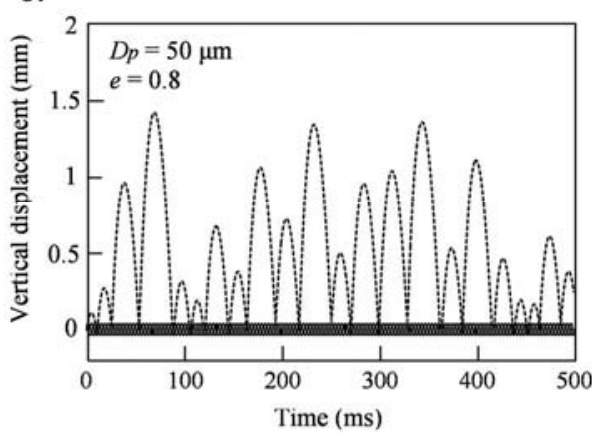

c.

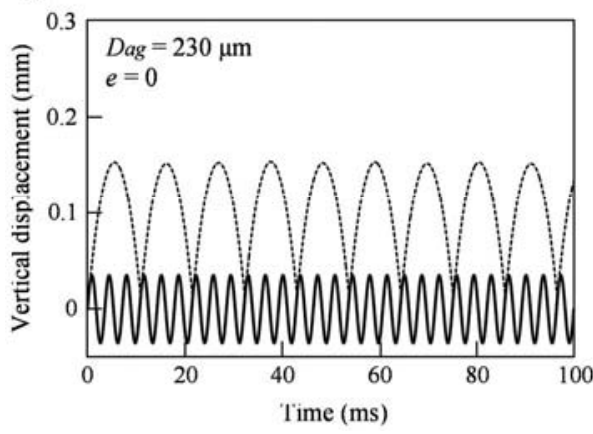

FIGURE 3. Vertical trajectory of particle and vibrating substrate (vibrating substrate: $f=280 \mathrm{~Hz}, A_{y}=35 \mu \mathrm{m}$ ).

Figure 3 (a) -(c) shows the vertical trajectory of the particles obtained from the numerical calculations. Restitution coefficients for the calculations are $0.8,0.8$ and 0 for $D_{p 50}=500 \mu \mathrm{m}, 50 \mu \mathrm{m}$ and $D_{\text {ag } 50}=230 \mu \mathrm{m}$, respectively. The saltation heights of the particles calculated by the model are in good agreement with the results shown in Table 2. A comparison between Figure 3 (a) and (b) shows that the smaller particle saltates in a lower height range owing to the effect of the drag force during flight. Figure 3 (c) shows that the small agglomerated particle saltates in the lowest height range. This is because the agglomerated particle adheres to the substrate at the collision. As a result, the flight is controlled by the velocity and acceleration of the vibrating substrate after the collision.

\section{CONCLUSION}

The observation by the high-speed digital camera shows that larger particles saltate higher, while smaller particles form small agglomerated particles, which slightly saltate. The saltation height ranges of the particles obtained experimentally is in good agreement with the results calculated by the model based on gravity, adhesion, drag force, and restitution. The model shows that the saltation heights of the agglomerated particles are determined by the velocity and acceleration of the vibrating substrate.

\section{NOMENCLATURE}

$A_{x} \quad$ horizontal vibration amplitude

(m)

$A_{y} \quad$ vertical vibration amplitude

$D_{p} \quad$ diameter of primary particle

$D_{p 50}$ mass median diameter of primary particle

$D_{a g}$ diameter of agglomerated particle

$D_{a g 50}$ mass median diameter of agglomerated particle

$e \quad$ coefficient of restitution between particle and substrate

$F_{a}$ adhesive force between particle and substrate

$F_{g} \quad$ gravity force

$F_{d} \quad$ fluid resistance force

$f \quad$ vibration frequency

$m_{p}$ mass of particle

$t$ time

$t_{0} \quad$ time at start of flight

$v_{y s} \quad$ vertical velocity of substrate

$v_{p} \quad$ vertical velocity of particle

$y_{s} \quad$ vertical displacement of substrate

$\alpha_{y s} \quad$ vertical acceleration of substrate

$\omega \quad$ vibration angular velocity $(=2 \pi f)$

$\left(\mathrm{m} / \mathrm{s}^{2}\right)$ particle density

$\left(\mathrm{kg} / \mathrm{m}^{3}\right)$

\section{Subscripts}

1 before collision

2 after collision

\section{ACKNOWLEDGMENTS}

This research was supported by a Grant no. S0901039 from MEXT, Japan. The authors are thankful to Taimei Chemicals Co., Ltd., Fujimi Incorporated for providing particles. 


\section{REFERENCES}

1. P. Pieranski, J. Physique. 44, 573-578 (1983).

2. C.N. Bapat, S. Sankar and N. Popplewell, Journal of Sound and Vibration. 108, 99-115 (1986).

3. E. Clement, S. Luding and A. Blumen, International Journal of Modern Physics B. 7, 1807-1827 (1993).

4. S. Luding, E. Clement and A. Blumen, Physical Review E. 49, 1634-1646 (1994).

5. C.J. Albert and P.S. Ray, Nonlinear dynamics. 10, 1-18 (1996). 